\title{
B. BubR1 insufficiency causes early onset of aging-associated phenotypes and infertility in mice
}

\author{
Darren J Baker ${ }^{1,2}$, Karthik B Jeganathan ${ }^{1,2}$, J Douglas Cameron ${ }^{3}$, Michael Thompson ${ }^{1,2}$, Subhash Juneja ${ }^{2}$, \\ Alena Kopecka ${ }^{1}$, Rajiv Kumar ${ }^{2,4}$, Robert B Jenkins ${ }^{5}$, Piet C de Groen ${ }^{4}$, Patrick Roche ${ }^{5} \&$ Jan M van Deursen ${ }^{1,2}$
}

Faithful segregation of replicated chromosomes is essential for maintenance of genetic stability and seems to be monitored by several mitotic checkpoints. Various components of these checkpoints have been identified in mammals, but their physiological relevance is largely unknown. Here we show that mutant mice with low levels of the spindle assembly checkpoint protein BubR1 develop progressive aneuploidy along with a variety of progeroid features, including short lifespan, cachectic dwarfism, lordokyphosis, cataracts, loss of subcutaneous fat and impaired wound healing. Graded reduction of BubR1 expression in mouse embryonic fibroblasts causes increased aneuploidy and senescence. Male and female mutant mice have defects in meiotic chromosome segregation and are infertile. Natural aging of wild-type mice is marked by decreased expression of BubR1 in multiple tissues, including testis and ovary. These results suggest a role for BubR1 in regulating aging and infertility.

In humans, aueuploidy is a hallmark of spontaneous abortions, birth defects and most cancers ${ }^{1-3}$. Accurate separation of duplicated chromosomes is ensured by the spindle assembly checkpoint, which prevents anaphase onset until each kinetochore has attached to mitotic spindle microtubules ${ }^{4-6}$. To determine the physiological role of the spindle assembly checkpoint protein BubR1, encoded by Bub1b, we

Figure 1 Cachectic dwarfism and short lifespan in BubR1-insufficient mice. (a) Schematic representation of the Bub1b gene-targeting strategy. Part of the Bub1b locus (+), the targeting vector with loxP sites (open triangles), the hypomorphic (H) and knockout (-) Bub1b alleles, BamHI restriction sites (B) and the Southern blot probe are indicated. (b) Southern-blot analysis of mice with indicated Bub1b genotypes. The 15-kb and 10-kb fragments represent the wild-type and hypomorphic alleles, respectively. (c) Growth curves of Bubl $b^{+/+}, B u b 1 b^{+/ / H}$ and Bub1 $b^{H / H}$ mice. (d) Western-blot analysis of MEFs, testis and thymus from mice carrying the indicated $B u b 1 b$ alleles with antibodies against BubR1 ( $\alpha$-tubulin and $\beta$-actin were used for loading control). (e-h) Photographs of $B u b 1 b^{H / H}$ and $B u b 1 b^{+/+}$mice at indicated ages. (i) Survival analysis of $B u b 1 b^{H / H}(n=212), B u b 1 b^{+/ H}(n=108$, two animals died before 15 months), Bub1 $b^{+/-}(n=43)$ and Bub1 $b^{+/+}(n=50)$ mice. produced a series of mice in which expression of BubR1 is reduced in graded fashion from normal levels to zero by the use of wild-type $\left(B u b 1 b^{+}\right)$, knockout $\left(B u b 1 b^{-}\right)$and hypomorphic $\left(B u b 1 b^{\mathrm{H}}\right)$ alleles (Fig. 1a,b and Supplementary Methods and Supplementary Fig. 1 online). As previously described ${ }^{7}$, complete loss of BubR1 caused early embryonic lethality (data not shown). Bublb $b^{-/ \mathrm{H}}$ mice died within several hours of birth, seemingly due to respiratory insufficiency, whereas $B u b 1 b^{\mathrm{H} / \mathrm{H}}$ mice survived to adulthood. $B u b 1 b^{\mathrm{H} / \mathrm{H}}$ mice were normal in appearance and size at birth but had slow postnatal growth (Fig. 1c). $B u b 1 b^{+/-}$and $B u b 1 b^{+/ H}$ mice had no overtly abnormal phenotypes
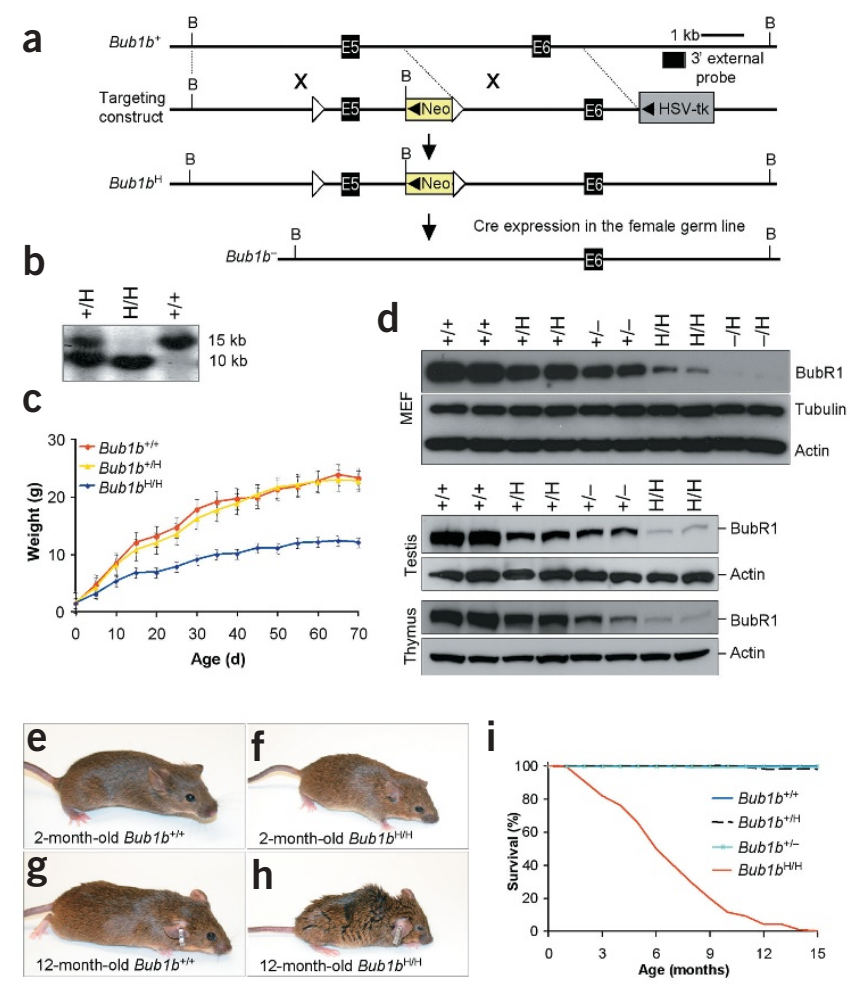

Departments of ${ }^{1}$ Pediatric and Adolescent Medicine, ${ }^{2}$ Biochemistry and Molecular Biology, ${ }^{3}$ Ophthalmology, ${ }^{4}$ Medicine and ${ }^{5}$ Pathology, Mayo Clinic, 200 First Street SW, Rochester, Minnesota 55905, USA. Correspondence should be addressed to J.M.v.D. (vandeursen.jan@mayo.edu). 
(Supplementary Fig. 2 online). Decreased expression of BubR1 was confirmed by western-blot analysis (Fig. 1d). BubR1 signals from $B u b 1 b^{+/ \mathrm{H}}, B u b 1 b^{+/-}, B u b 1 b^{\mathrm{H} / \mathrm{H}}$ and $B u b 1 b^{-/ \mathrm{H}}$ mouse embryonic fibroblasts (MEFs) were $42 \%$ ( $\pm 15 \%), 29 \%( \pm 9 \%), 11 \%( \pm 3 \%)$ and $4 \%$ ( $\pm 2 \%)$, respectively, of those from $B u b 1 b^{+/+}$MEFs.

We monitored $50 \mathrm{Bublb}^{+/+}, 108 \mathrm{Bublb}^{+/ \mathrm{H}}, 43 \mathrm{Bublb}^{+/-}$and 230 $B u b 1 b^{\mathrm{H} / \mathrm{H}}$ mice to $15-16$ months of age. One $B u b 1 b^{\mathrm{H} / \mathrm{H}}$ mouse developed a life-threatening tumor. Six of 116 moribund or deceased $B u b 1 b^{\mathrm{H} / \mathrm{H}}$ mice had solitary tumors at autopsy. $B u b 1 b^{\mathrm{H} / \mathrm{H}}$ mice had a normal appearance until 2-3 months of age (Fig. 1f; compare with wildtype mouse in Fig. 1e) but typically developed cachexia and lordokyphosis at 3-6 months of age (Fig. 1h and Supplementary Fig. 2 online; compare with wild-type mouse in Fig. 1g). The median lifespan of $B u b 1 b^{\mathrm{H} / \mathrm{H}}$ mice was $\sim 6$ months, compared with more than 15 months a

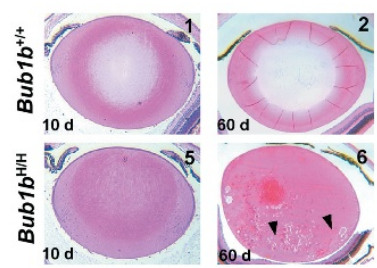

b

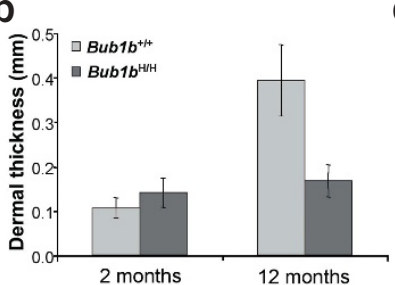

d

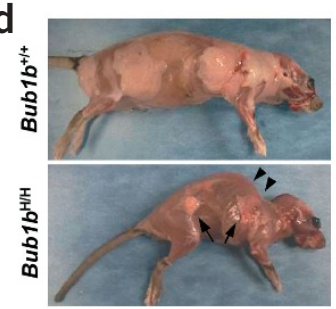

f

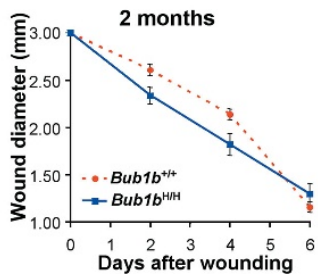

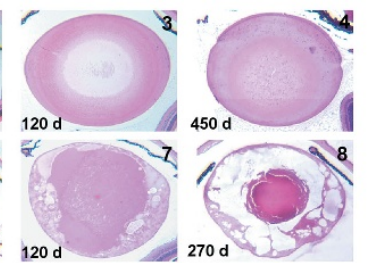

C

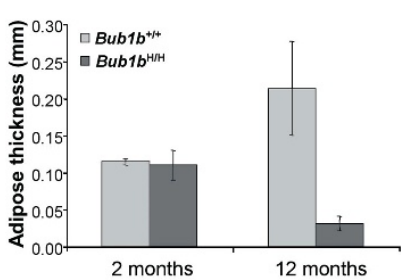

e
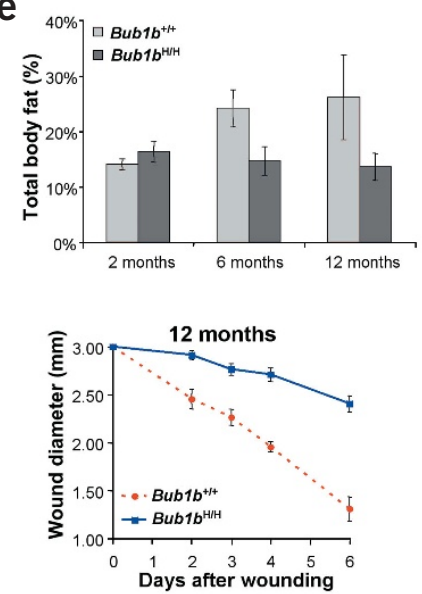

Figure 2 Aging phenotypes in $B u b 1 b^{\mathrm{H} / \mathrm{H}}$ mice. (a) Cross-sections of lenses from $B u b 1 b^{\mathrm{H} / \mathrm{H}}$ and $\mathrm{Bub} 1 b^{+/+}$mice at various ages stained with hematoxylin and eosin. $B u b 1 b^{\mathrm{H} / \mathrm{H}}$ lenses were normal at day 10 but showed Morgagnian globules at day 60 (arrowheads), overt cataracts at day 120 and advanced stage nuclear cataracts at day 270. (b) Dermal layer thickness of $B u b 1 b^{H / H}$ and $B u b 1 b^{+/+}$mice at indicated ages ( $n=3$ mice per group).

(c) Subcutaneous adipose layer thickness of $B u b 1 b^{\mathrm{H} / \mathrm{H}}$ and $B u b 1 b^{+/+}$mice at indicated ages ( $n=3$ mice per group). (d) Skinned 9-month-old Bub1 $b^{+/+}$ (top) and $B u b 1 b^{\mathrm{H} / \mathrm{H}}$ (bottom) females. The $B u b 1 b^{\mathrm{H} / \mathrm{H}}$ mouse had little subcutaneous fat (arrows) and pronounced kyphosis (arrowheads).

(e) Analysis of total body fat of $B u b 1 b^{+/+}$and $B u b 1 b^{\mathrm{H} / \mathrm{H}}$ females at indicated ages ( $n=3$ mice per genotype and age group). (f) Closure of 3-mm punch biopsy wounds in $\mathrm{Bub} 1 \mathrm{~b}^{+/+}$and $\mathrm{Bub} 1 \mathrm{~b}^{\mathrm{H} / \mathrm{H}}$ mice at 2 months (left panel) and 12 months (right panel) of age. for $B u b 1 b^{+/-}, B u b 1 b^{+/ H}$ and $B u b 1 b^{+/+}$mice (Fig. 1i). At age 2 months and older, $B u b 1 b^{\mathrm{H} / \mathrm{H}}$ mice developed progressive bilateral cataracts with features reminiscent of age-related human cataracts (Fig. 2a). No cataracts were observed in $\mathrm{Bublb} b^{+/-}, \mathrm{Bublb} b^{+/ \mathrm{H}}$ or $\mathrm{Bublb^{+/+ }}$ mice. Histological analysis of skin showed that the dermis and subcutaneous fat cell layers were significantly thinner in 12-month-old $B u b 1 b^{\mathrm{H} / \mathrm{H}}$ mice than in control mice (Fig. 2b,c and Supplementary Fig. 2 online). Skinning of $B u b 1 b^{\mathrm{H} / \mathrm{H}}$ mice confirmed substantial loss of subdermal adipose tissue and highlighted their severe spinal kyphosis and muscle atrophy (Fig. 2d). Dual-energy X-ray absorptiometry measurements confirmed that total body fat of $B u b 1 b^{\mathrm{H} / \mathrm{H}}$ mice declined prematurely (Fig. 2e). Bub1b $b^{\mathrm{H} / \mathrm{H}}$ mice also had less ability to repair wounds at an early age (Fig. 2f). Taken together, these results (Supplementary Table 1 online) suggest that multiple aging-associated phenotypes develop early in mice expressing BubR1 below a threshold level.

To investigate whether the progeroid phenotypes could be due to a defective spindle assembly checkpoint, we measured the ability of $B u b 1 b$-mutant MEFs to induce a sustained preanaphase arrest in the presence of nocodazole. Approximately $11-12 \%$ of $B u b 1 b^{+/+}$, $B u b 1 b^{+/ H}$ and $B u b 1 b^{+/-}$MEFs were arrested by $12 \mathrm{~h}$ (Fig. 3a). In

\section{a}

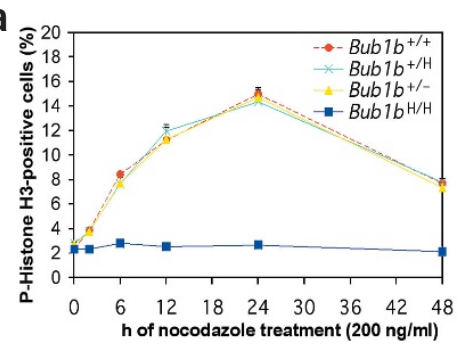

C

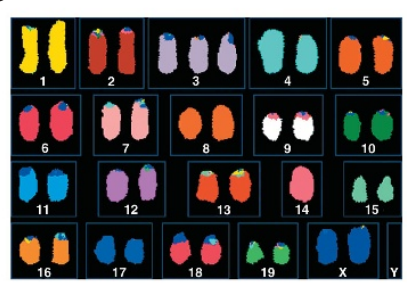

e

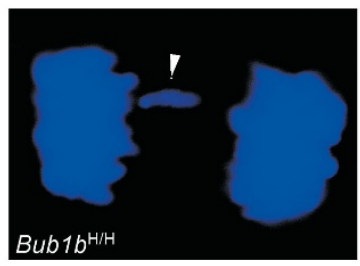

b

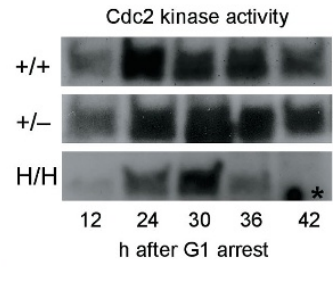

d

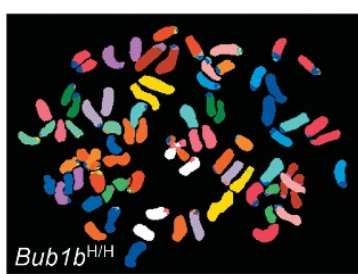

f

\begin{tabular}{lc}
\hline Genotype & $\begin{array}{c}\text { Percentage of } \\
\text { metaphases with } \\
\text { lagging chromosomes }\end{array}$ \\
\hline Bub1 $b^{+/+}$ & $3 \%( \pm 1)$ \\
$B u b 1 b^{+/ H}$ & $4 \%( \pm 0)$ \\
$B u b 1 b^{+/-}$ & $5 \%( \pm 1)$ \\
$B u b 1 b^{H / H}$ & $12 \%( \pm 2)$ \\
$B u b 1 b^{-H H}$ & $16 \%( \pm 3)$ \\
\hline
\end{tabular}

Figure $3 \mathrm{Bub} 1 \mathrm{~b}^{\mathrm{H} / \mathrm{H}}$ cells have mitotic checkpoint defects. (a) Mitotic index (defined as the percentage of mitotic cells) of nocodazole-treated MEF lines of indicated genotypes ( $n=3$ for each genotype). The growth rates of these MEF lines were similar (growth curves not shown). (b) Cyclin B-associated Cdc2 kinase activity of synchronized MEF cells at indicated time points after release into medium with high serum and nocodazole. The asterisk marks an aspecific spot on the autoradiogram. (c) Spectral karyotype of a numerically normal $B u b 1 b^{\mathrm{H} / \mathrm{H}}$ metaphase with a gain of chromosome 3 and a loss of chromosome 14. (d) Spectral image of a Bub1 $b^{\mathrm{H} / \mathrm{H}}$ metaphase (MEF) that shows PMSCS. (e) Bub1 $b^{\mathrm{H} / \mathrm{H}} \mathrm{MEF}$ cell with a lagging chromosome in anaphase. DNA was stained with Hoechst. The arrowhead highlights a lagging chromosome. (f) The average percentage of anaphases with lagging chromosomes per genotype. 
contrast, only $2.5 \%$ of $B u b 1 b^{\mathrm{H} / \mathrm{H}}$ MEFs were arrested by $12 \mathrm{~h}$, suggesting that spindle assembly checkpoint function was severely compromised. We confirmed this result by flow cytometry (Supplementary Fig. 3 online). Next, we synchronized MEFs in G1 and analyzed their cyclin B-associated Cdc2 kinase activity after releasing them into medium with nocodazole. $B u b 1 b^{\mathrm{H} / \mathrm{H}}$ cells had high Cdc2 kinase activity by $24-30 \mathrm{~h}$ after release, similar to Bublb $b^{+/+}$cells (Fig. 3 b). Bubl $b^{+/+}$cells sustained high levels of Cdc2 activity until $42 \mathrm{~h}$ after restimulation, but $B u b 1 b^{\mathrm{H} / \mathrm{H}}$ cells did not maintain activity after $30 \mathrm{~h}$, consistent with a spindle assembly checkpoint defect ${ }^{8,9}$.

The average percentage of aneuploid metaphases was much higher in passage 5 (P5) Bubl $b^{\mathrm{H} / \mathrm{H}}$ MEFs than in $\mathrm{P} 5 \mathrm{Bublb}^{+/-}, \mathrm{Bublb}^{+/ \mathrm{H}}$ and $B u b 1 b^{+/+}$MEFs (Table 1a). We observed even more profound aneuploidy in $\mathrm{P} 5 \mathrm{Bub} 1 b^{-/ \mathrm{H}}$ MEFs. We also carried out spectral karyotype analysis on metaphase spreads from $B u b 1 b^{+/+}$and $B u b 1 b^{\mathrm{H} / \mathrm{H}}$ MEFs. $B u b 1 b^{+/+}$metaphases $(n=9)$ were karyotypically normal. In contrast, five of ten $B u b 1 b^{\mathrm{H} / \mathrm{H}}$ metaphases had numerical abnormalities. Furthermore, two numerically normal $B u b 1 b^{\mathrm{H} / \mathrm{H}}$ metaphases showed loss of one chromosome and gain of another (Fig. 3c). We observed premature sister chromatid separation (PMSCS), a hallmark of a defective spindle assembly checkpoint ${ }^{8,9}$, in $38 \%$ and $15 \%$ of mitotic figures from $B u b 1 b^{-/ \mathrm{H}}$ and $B u b 1 b^{\mathrm{H} / \mathrm{H}}$ MEFs, respectively, but in only $1-3 \%$ of $B u b 1 b^{+/-}, B u b 1 b^{+/ H}$ and $B u b 1 b^{+/+}$MEFs (Table 1a and Fig. 3d). As expected, we observed more anaphase figures with lagging chromosomes in $B u b 1 b^{-/ H}$ and $B u b 1 b^{\mathrm{H} / \mathrm{H}}$ cells than in $B u b 1 b^{+/-}$,

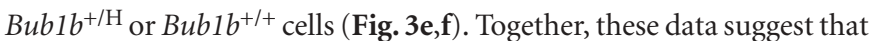
the accuracy of chromosome segregation is greatly affected when BubR1 levels drop below a certain level.

$B u b 1 b^{-/ H}$ pups showed substantial aneuploidy at birth, but $B u b 1 b^{\mathrm{H} / \mathrm{H}}$ mice did not (Table $1 \mathbf{b}$ ). At age 2 months, however, $B u b 1 b^{\mathrm{H} / \mathrm{H}}$ mice had developed mild aneuploidy that increased in both degree and severity as mice aged further. $B u b 1 b^{+/-}$and $B u b 1 b^{+/ H}$ mice did not have detectable aneuploidy. We observed no genome maintenance defects other than chromosome number instability in $\mathrm{Bub} 1 b^{\mathrm{H} / \mathrm{H}}$ and $\mathrm{Bublb}^{-/ \mathrm{H}}$ cells (Table 1a and Supplementary Fig. 4 online). The strong correlation between the onset and progression of the agingassociated phenotypes and the degree and the severity of the chromosome number instability in $\mathrm{Bub} 1 b^{\mathrm{H} / \mathrm{H}}$ mice are suggestive of a role for aneuploidy stemming from BubR1 dysfunction in the development of progeroid features.

We next determined whether BubR1 deficiency triggers apoptosis or cellular senescence, two responses that have been linked to aging ${ }^{10,11}$. We found similar numbers of apoptotic cells in kidney, liver and lung sections from 1-year-old $B u b 1 b^{\mathrm{H} / \mathrm{H}}$ and $B u b 1 b^{+/+}$mice, and in $B u b 1 b^{\mathrm{H} / \mathrm{H}}$ and $B u b 1 b^{+/+}$MEF cultures (data not shown). Senescence-associated $\beta$-galactosidase activity was high in kidney sections from 5-month-old $B u b 1 b^{\mathrm{H} / \mathrm{H}}$ mice, but not in those from age-matched $\mathrm{Bublb}^{+/+}$mice and 2-month-old $\mathrm{Bublb} b^{\mathrm{H} / \mathrm{H}}$ mice (Fig. 4a). $\mathrm{P} 3 \mathrm{Bublb} \mathrm{b}^{\mathrm{H} / \mathrm{H}} \mathrm{MEFs}$ had comparable growth rates (Fig. 4d) and numbers of cells positive for senescence-associated $\beta$-galactosidase activity to those of $\mathrm{Bublb}^{+/+} \mathrm{MEFs}$ (Fig. 4b). At P7, however,

\section{Table 1 Gradual reduction of BubR1 causes progressively more aneuploidy in MEFs and mice}

(a)

\begin{tabular}{|c|c|c|c|c|c|c|c|c|c|c|c|c|c|c|c|}
\hline $\begin{array}{c}\text { Mitotic } \\
\text { MEF } \\
\text { genotype }(n)\end{array}$ & $\begin{array}{c}\text { Percent } \\
\text { figures } \\
\text { inspected }\end{array}$ & $\begin{array}{l}\text { Aneuploid } \\
\text { figures }\end{array}$ & s.d. & 38 & 39 & aryotype & indic & chror & ne nu & 44 & 45 & $\begin{array}{l}\text { Percent } \\
\text { mitotic } \\
\text { figures with } \\
\text { PMSCS }\end{array}$ & s.d. & $\begin{array}{c}\text { Percent } \\
\text { mitotic } \\
\text { figures with } \\
\text { breaks }\end{array}$ & $\begin{array}{c}\text { Percent } \\
\text { mitotic } \\
\text { figures with } \\
\text { fusions }\end{array}$ \\
\hline $\mathrm{Bublb}^{+/+}(6)$ & 300 & $9(11)^{a}$ & $2(3)$ & & 4 & 137 & 9 & & & & & $2(2)^{a}$ & $1(1)$ & 1 & 0 \\
\hline Bublb $b^{+/ H}(3)$ & 150 & 8 & 2 & & 4 & 138 & 8 & & 1 & & & 1 & 1 & ND & ND \\
\hline Bublb b/- (6) & 300 & 14 & 2 & & 9 & 128 & 12 & & 1 & & & 3 & 1 & ND & ND \\
\hline Bub1 $b^{H / H}$ (3) & 125 & $36(35)^{a}$ & $6(1)$ & 5 & 13 & 80 & 20 & 6 & 1 & & & $15(18)^{a}$ & $3(3)$ & 2 & 0 \\
\hline $\mathrm{Bublb}^{-/ \mathrm{H}}$ (3) & 100 & 72 & 4 & 3 & 11 & 28 & 20 & 17 & 14 & 5 & 2 & 43 & 4 & 0 & 0 \\
\hline
\end{tabular}

(b)

\begin{tabular}{|c|c|c|c|c|c|c|c|c|c|c|c|}
\hline \multirow{2}{*}{$\begin{array}{c}\text { Mouse } \\
\text { genotype }\end{array}$} & \multirow[b]{2}{*}{ Age $(n)$} & \multirow{2}{*}{$\begin{array}{c}\text { Mitotic } \\
\text { figures } \\
\text { inspected }\end{array}$} & \multirow{2}{*}{$\begin{array}{l}\text { Percent } \\
\text { aneuploid } \\
\text { figures }\end{array}$} & \multirow[b]{2}{*}{ s.d. } & \multicolumn{5}{|c|}{ Karyotypes with indicated chromosome number } & \multirow{2}{*}{$\begin{array}{l}\text { Percent mitotic } \\
\text { figures with } \\
\text { PMSCS }\end{array}$} & \multirow[b]{2}{*}{ s.d. } \\
\hline & & & & & 38 & 39 & 40 & 41 & 42 & & \\
\hline \multirow[t]{4}{*}{ Bub1 $b^{+/+}$} & 1 day $(5)^{b}$ & 250 & 0 & 0 & & & 250 & & & 1 & 1 \\
\hline & 2 months (5) & 250 & 0 & 0 & & & 250 & & & 0 & 0 \\
\hline & 5 months (4) & 200 & 0 & 0 & & & 200 & & & 0 & 0 \\
\hline & 1 year $(3)$ & 150 & 0 & 0 & & & 150 & & & 1 & 1 \\
\hline \multirow[t]{2}{*}{$B u b 1 b^{+/ H}$} & 1 day $(3)^{b}$ & 150 & 0 & 0 & & & 150 & & & 0 & 0 \\
\hline & 1 year (3) & 150 & 0 & 0 & & & 150 & & & 0 & 0 \\
\hline \multirow[t]{2}{*}{ Bubl $1 b^{+/-}$} & 1 day $(4)^{b}$ & 200 & 0 & 0 & & & 200 & & & 2 & 2 \\
\hline & 1 year (3) & 150 & 0 & 0 & & & 150 & & & 5 & 5 \\
\hline \multirow[t]{5}{*}{$B u b 1 b^{\mathrm{H} / \mathrm{H}}$} & 1 day $(3)^{\mathrm{b}}$ & 150 & 0 & 0 & & & 150 & & & 30 & 7 \\
\hline & 2 months (7) & 315 & 3 & 2 & & 3 & 310 & 2 & & 38 & 7 \\
\hline & 3 months ( 3 ) & 125 & 9 & 2 & & 4 & 114 & 6 & 1 & 35 & 2 \\
\hline & 5 months (4) & 200 & 15 & 4 & 2 & 12 & 170 & 16 & & 35 & 4 \\
\hline & 12 months (5) & 250 & 33 & 4 & 9 & 22 & 168 & 44 & 7 & 24 & 4 \\
\hline Bubl $b^{-/ H}$ & 1 day $(3)^{b}$ & 150 & 21 & 1 & 1 & 10 & 117 & 21 & 1 & 43 & 2 \\
\hline
\end{tabular}

avalues in parentheses were derived from independently generated MEF lines cultured in $3 \%$ oxygen (instead of $20 \%$ oxygen). bSpleens did not contain sufficient cells for karyotyping at day 1 and livers were used at this age.

(a) Analysis of numerical and structural chromosomal abnormalities in P5 MEFs of indicated genotypes. Spectral karyotype analysis showed that the incidence of chromosomal translocations in Bub1 $b^{+/+}$and Bub1 $b^{\mathrm{H} / \mathrm{H}}$ MEFs was similar (data not shown). ND, not done. (b) Aneuploidy and PMSCS in liver cells from newborn pups and splenocytes from adult mice of indicated genotypes and ages. 
a

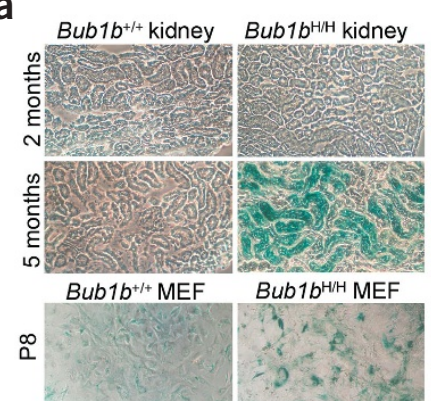

d

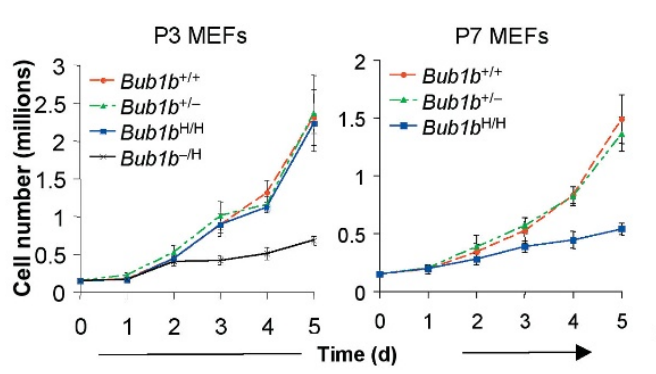

b

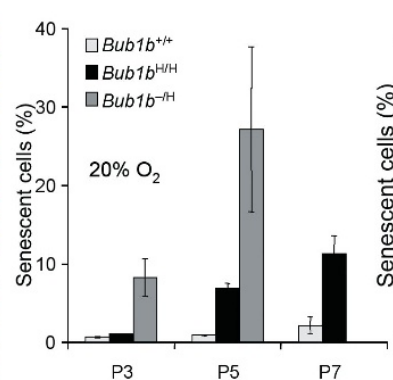

e

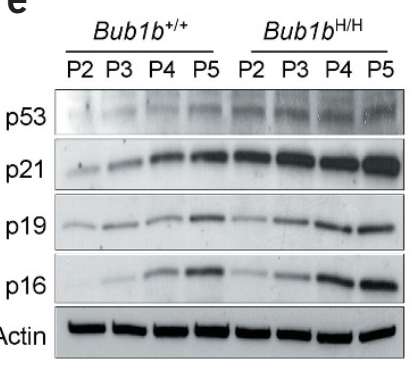

Figure 4 BubR 1 insufficiency causes early onset of senescence. (a) Senescence-associated $\beta$ galactosidase activity in kidney sections of 2 - and 5-month-old Bubl $b^{\mathrm{H} / \mathrm{H}}$ and $\mathrm{Bub} 1 b^{+/+}$mice, and in P8 Bubl $b^{\mathrm{H} / \mathrm{H}}$ and $\mathrm{Bubl} b^{+/+}$MEFs. (b) Percentages of $B u b 1 b^{-/ H}, B u b 1 b^{\mathrm{H} / \mathrm{H}}$ and Bub $1 b^{+/+}$MEF cells cultured in $20 \%$ oxygen that were positive for senescence-associated $\beta$ galactosidase activity. Passages at which measurements were made are indicated. (c) Percentages of MEF cells of indicated genotypes cultured in 3\% oxygen that were positive for senescence-associated $\beta$ galactosidase activity. (d) Growth curves of P3 (left panel) and P7 (right panel) MEF cells of indicated genotypes. (e) Expression of senescence-associated markers in $\mathrm{Bub} 1 b^{\mathrm{H} / \mathrm{H}}$ and Bub1 $b^{+/+}$MEF cells at P2-P5.
$B u b 1 b^{\mathrm{H} / \mathrm{H}}$ MEF cultures had substantially slower growth rates and more cells positive for senescence-associated $\beta$-galactosidase activity

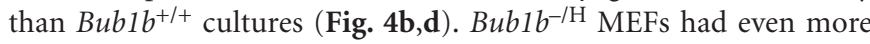
profound growth inhibition and senescence-associated $\beta$-galactosidase activity (Fig. 4b,d), suggesting that the rate of senescence correlates with the degree of aneuploidy. Bub $1 b^{\mathrm{H} / \mathrm{H}}$ MEFs senesced quickly in both $20 \%$ and $3 \%$ oxygen (Fig. 4c), indicating that oxidative DNA damage $^{12}$ is an unlikely cause of the senescence phenotype. $B u b 1 b^{\mathrm{H} / \mathrm{H}}$ MEFs showed early accumulation of the senescence markers p53, p21, p16 and p19 (Fig. 4e). Taken together, these results suggest that aneuploidy in cells from BubR1-insufficient mice might elicit signals that drive them into a senescent state and cause early aging-related phenotypes as they accumulate.

$B u b 1 b^{\mathrm{H} / \mathrm{H}}$ mice did not produce any pregnancies. Testicular weight of $B u b 1 b^{\mathrm{H} / \mathrm{H}}$ males $(0.088 \mathrm{~g} \pm 0.009 ; n=8$ testes) was slightly below that of $B u b 1 b^{+/+}$males $(0.106 \mathrm{~g} \pm 0.006 ; n=8$ testes $)$. Testes of 4-month-old $B u b 1 b^{\mathrm{H} / \mathrm{H}}$ mice were histologically normal (data not shown), but sperm counts of $B u b 1 b^{\mathrm{H} / \mathrm{H}}$ mice $\left(9.3 \times 10^{6} \pm 2.6 \times 10^{6} ; n\right.$ $=3$ ) were about four times lower than those of $B u b 1 b^{+/+}$mice (37.1 $\left.\times 10^{6} \pm 8 \times 10^{6} ; n=3\right) . B u b 1 b^{\mathrm{H} / \mathrm{H}}$ spermatozoa had normal motility and morphology (data not shown) and were able to attach to and fertilize $\mathrm{Bublb}^{+/+}$eggs in vitro, but they produced 2-cell-stage embryos at 13 times less frequently than $B u b 1 b^{+/+}$spermatozoa (Fig. 5a). Chromosome counts on metaphases of spermatocytes in meiosis II showed that $5 \%$ of $B u b 1 b^{\mathrm{H} / \mathrm{H}}$ karyotypes had abnormal chromosome numbers compared with $0 \%$ of $B u b 1 b^{+/+}$karyotypes (Fig. 5b). Thus, reduced expression of BubR1 seems to affect male fertility at the levels of meiotic chromosome segregation, sperm number and fertilization.

Ovaries from 4-month-old $\mathrm{Bub} 1 b^{\mathrm{H} / \mathrm{H}}$ mice appeared histologically normal (data not shown) and were capable of producing mature eggs that arrested at metaphase of meiosis II. But we observed highly abnormal metaphase II configurations in 9 of 13 arrested $B u b 1 b^{\mathrm{H} / \mathrm{H}}$ oocytes (Fig. 5c). Oocytes from age-matched Bublb $b^{+/+}$mice $(n=14)$ yielded normal metaphase II configurations. We conclude that infertility in female mice expressing low levels of BubR1 is caused, at least in part, by meiotic chromosome segregation defects.
To determine whether reduced expression of BubR1 might have a role in natural aging, we measured BubR1 levels in wild-type mice of various ages. BubR1 was high in testes of 4-month-old mice but gradually decreased to very low levels as mice aged up to 32 months (Fig. 5d). In contrast, the spindle assembly checkpoint proteins Bub3 and Rae1 remained highly expressed as mice aged (Fig. 5d). Reductions in BubR1 expression were also seen in ovaries and spleens of 22-month-old mice, but not in lungs (Fig. 5e,f and data not shown). Overall, these data are consistent with the idea that BubR1 might have a role in normal aging. The finding that very few $B u b 1 b^{\mathrm{H} / \mathrm{H}}$ mice had detectable tumors when they died, despite substantial chromosome number instability, is unexpected because aneuploidy is a hallmark of most human cancers $^{3,13,14}$, and because $B u b 1 b$ is mutated or expressed at low levels in a subset of colorectal carcinomas with chromosomal instability $^{15,16}$. Instead, BubR1-deficient mice have early onset of several aging-associated phenotypes and have severely shortened lifespans. This, together with the demonstration that BubR1 expression declines in several tissues as wild-type mice age, suggests that this checkpoint protein may be a key regulator of normal aging. Reproductive aging in female mammals occurs relatively early in life and is characterized by the production of increasing numbers of aneuploid oocytes. In humans, this leads to increased abortions and birth defects, such as Down syndrome ${ }^{1}$. Chromosomal segregation defects associated with reproductive aging are reminiscent of those seen in oocytes of mutant mice expressing low levels of BubR1. Given this age-dependent decline in ovarian BubR1, we propose that downregulation of BubR1 might be a mechanism that contributes to age-related female infertility and certain birth defects. Paternal fertility also declines with advancing age ${ }^{17,18}$, and a regulatory role for BubR1 is certainly conceivable, given the decline in BubR1 levels in testes of aging normal mice and the negative impact of BubR1-deficiency on fertility of male mutant mice.

\section{METHODS}

Generation of BubR1 mutant mice. We used a previously reported gene targeting strategy to create a hypomorphic $B u b 1 b$ allele in mouse embryonic stem cells $^{19}$ (for details, see Supplementary Methods and Supplementary Fig. 1 
Figure 5 Analysis of BubR1 in testis and ovary of mutant and normal mice. (a) In vitro fertilization experiments with eggs from $B u b 1 b^{+/+}$females and sperm from Bub1 $1 b^{+/+}$or Bub1 $b^{\mathrm{H} / \mathrm{H}}$ males. (b) Karyotype analysis of $\mathrm{Bub}_{1} \mathrm{~b}^{+/+}$and $\mathrm{Bub} 1 \mathrm{~b}^{\mathrm{H} / \mathrm{H}}$ spermatocytes at prometaphase of meiotic division II. Abnormal Bub1 $b^{\mathrm{H} / \mathrm{H}}$ karyotypes showed either a gain or loss of one duplicated chromosome. (c) Oocytes from Bub $1 b^{\mathrm{H} / \mathrm{H}}$ mice arrested at metaphase II stained with $\alpha$-tubulin and Hoechst. Normal metaphase configuration (left panel), metaphase with misaligned chromosomes (middle panel) and metaphase with an extra spindle (arrow) and misaligned chromosomes (arrowheads; right panel) are shown. (d) Western-blot analyses of BubR1 levels in testis of young and old $\mathrm{Bubl} \mathrm{b}^{+/+}$mice.

(e) Western-blot analyses of BubR1 levels in ovary of young and old Bubl $\mathrm{b}^{+/+}$mice. (f) Crosssections through ovary from young and old $\mathrm{Bub}_{1} \mathrm{~b}^{+/+}$mice immunostained for BubR1 (green) and DNA (blue). Representative corpora lutea are shown.
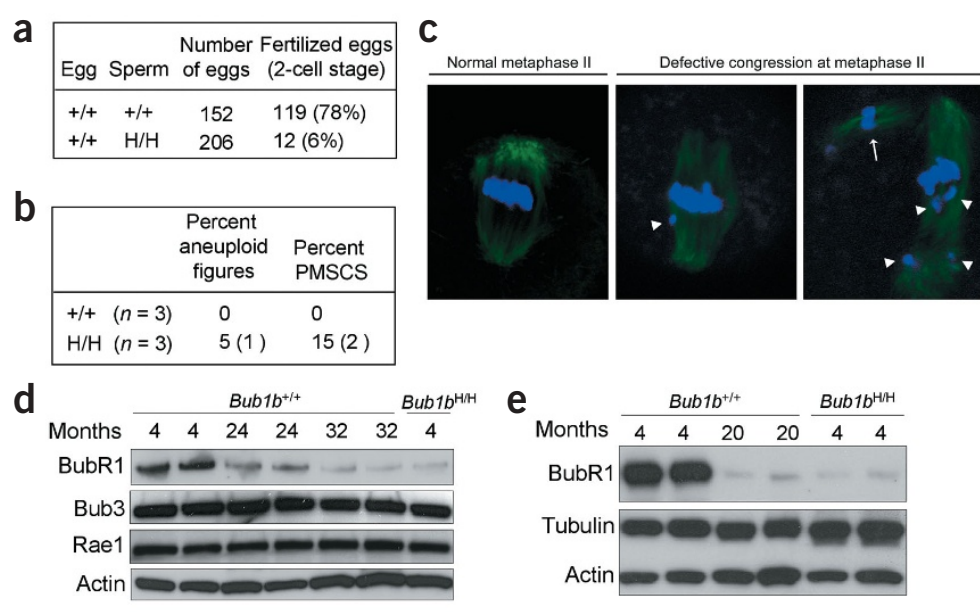

f
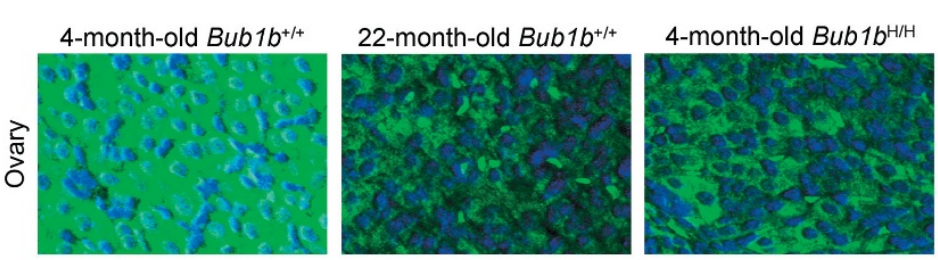

online). $B u b 1 b^{\mathrm{H} / \mathrm{H}}$ mice obtained from four independently targeted embryonic stem cell clones had identical phenotypes. We monitored body weight in ten females of each genotype for $70 \mathrm{~d}$. All mice were housed in a pathogen-free barrier environment for the duration of the study. Experimental procedures involving laboratory mice were reviewed and approved by the Institutional Animal Care and Use Committee of the Mayo Clinic.

Western-blot analysis. We carried out western-blot analyses as previously described $^{20}$. We used affinity-purified rabbit antibody against mouse BubR1 (382-420) to detect BubR1. We quantified BubR1 signals ( $n=6$ per genotype) by the use of Bio-Rad Quantity One Software (version 4.1.0) and normalized them to $\beta$-actin (AC-151, Sigma; 1:40,000 dilution). We also probed some blots with $\alpha$-tubulin (T-9026, Sigma; 1:2,000 dilution) as a loading control. We used antibody against human BubR1 (1-350) to exclude production of truncated BubR1 products by $B u b 1 b^{\mathrm{H}}$ and $B u b 1 b^{-}$alleles. To quantify senescence-associated proteins in various MEF lysates, we used the following antibodies at 1:200 dilution (purchased from Santa Cruz unless noted otherwise): p16 (M-156; sc1207), p19 (NB200-106; Novus Biologicals), p21 (M-19; sc-471), p53 (Fl-393G, sc-6243-G). We detected Bub3 and Rael as previously described ${ }^{8}$.

Histopathology. We screened all major organs for overt tumors using a dissection microscope and processed the collected tumors routinely for histopathological confirmation. We fixed dissected tissues for histology in $10 \%$ formalin, processed them and embedded them in paraffin. We cut $5-\mu \mathrm{m}$ sections of all tissues and stained them with hematoxylin and eosin using standard procedures. We stained dorsal skin sections and determined the thickness of the dermal and adipose layers by taking 40 random measurements of each mouse for each genotype and age group $(n=3)$. Calculations were done using a calibrated computer program (Spot Advanced by BioSpot). We stained ovary sections with affinitypurified antibody against BubR1 (382-420) as previously described ${ }^{21}$.

Bone and fat analyses by dual-energy $\mathrm{X}$-ray absorptiometry. We analyzed bone mineral content, bone mineral density and total body adipose using a LUNAR PIXI-mus small animal densitometer (LUNAR Corporate Headquarters) as described ${ }^{22}$ in three anesthetized mice (with avertin) of each genotype and age.

Wound healing analysis. We analyzed the ability of mice to repair wounds as previously described ${ }^{23}$. We introduced 3-mm punch biopsy wounds into dorsal skin of anesthetized mice. For a period of $6 \mathrm{~d}$, we measured wound diameters using a digital caliper. Bubl $b^{\mathrm{H} / \mathrm{H}}$ mice did not survive at a standard anesthetic dose of $375 \mu \mathrm{g}$ of avertin per g body weight but did survive with half that dose.

Generation and culture of MEFs. We intercrossed $B u b 1 b^{+/ H}$ mice to derive $B u b 1 b^{+/+}, B u b 1 b^{+/ H}$ and Bubl $b^{\mathrm{H} / \mathrm{H}}$ MEFs from individual 13.5-d-old fetuses. We intercrossed $B u b 1 b^{+/-}$and $B u b 1 b^{+/+}$mice to generate $B u b 1 b^{+/+}$and $B u b 1 b^{+/-}$MEFs, and $B u b 1 b^{+/-}$and $B u b 1 b^{+/ H}$ mice to generate $B u b 1 b^{-/ H}$ MEFs. They were cultured in $20 \%$ oxygen, frozen at P2 and P3 and used for experimentation at indicated passages. For the studies described, we examined at least three $B u b 1 b^{\mathrm{H} / \mathrm{H}}, \mathrm{Bubl} b^{+/+}$and $\mathrm{Bubl} b^{+/-}$clones. We generated growth curves using P3 and P7 MEFs. At day 0, we plated $1.5 \times 10^{5}$ MEFs per 35-mm dish and counted duplicate cultures at 24-h intervals thereafter $(n=3 \mathrm{MEF}$ lines per genotype). In certain experiments, we wanted to limit senescence due to oxidative stress ${ }^{12}$, and so we used MEFs that were generated and cultured in 3\% oxygen. MEFs were synchronized as previously described ${ }^{8}$. We washed confluent cultures three times with phosphate-buffered saline and then cultured them in Dulbecco's modified Eagle medium containing $0.1 \%$ fetal bovine serum and $0.04 \%$ bovine serum albumin for $18 \mathrm{~h}$. We treated quiescent MEFs with trypsin and reseeded them in Dulbecco's modified Eagle medium with $10 \%$ fetal bovine serum to allow their reentry into the cell cycle.

Spindle assembly checkpoint analyses. We measured mitotic index $(n=3$ MEF lines per genotype) and carried out FACS-based analysis of spindle assembly checkpoint activity as previously described ${ }^{8}$. We carried out Cdc2-kinase assays as previously described ${ }^{24}$.

Karyotype analyses. We prepared metaphase spreads from MEFs and splenocytes and analyzed them for aneuploidy and PMSCS as previously described ${ }^{8}$. For chromosome number analysis of spermatocytes, we minced testes between two microscope slides and instantly prepared metaphase spreads from the resulting cell suspensions. We carried out spectral karyotypic analysis of MEFs using the protocol, reagents, instrumentation and software from Applied Spectral Imaging.

Analysis of DNA repair functions. We carried out DNA damage MEF survival experiments as described ${ }^{25,26}$. For mitomycin C (Sigma) and paraquat (Sigma) survival experiments, we seeded $10^{4} \mathrm{P} 2 \mathrm{MEFs}$ in triplicate in a 96well flat-bottom tissue culture dish. The next day, we replaced the medium 
with drug-containing medium and allowed cells to grow for $72 \mathrm{~h}$. For ultraviolet- $\mathrm{B}$ and $\gamma$-irradiation experiments, we exposed $2 \times 10^{4} \mathrm{P} 2 \mathrm{MEF}$ to various doses of ultraviolet-B or ionizing irradiation, seeded them in triplicate and cultured them for $72 \mathrm{~h}$. We measured cell survival by the use of the MTS assay (Promega). Data represent three independent MEF lines of each genotype. For $\gamma$-irradiation colony forming assays, we seeded $4 \times 10^{4} \mathrm{MEF}$ cells in duplicate in 10-cm tissue culture dishes and exposed them to various doses of ionizing radiation at $\mathrm{P} 2$. We grew cells in 3\% oxygen for $14 \mathrm{~d}$ and counted colonies. In the colony-forming assay after treatment with mitomycin $\mathrm{C}$, we seeded $4 \times 10^{4} \mathrm{P} 2 \mathrm{MEF}$ cells in duplicate in $10-\mathrm{cm}$ tissue culture dishes and allowed them to grow for $24 \mathrm{~h}$. The indicated concentration of medium containing mitomycin $\mathrm{C}$ was added and cells were allowed to grow for $14 \mathrm{~d}$ in $3 \%$ oxygen. For the highest doses of $\gamma$-irradiation and mitomycin C, we used five times as many cells. We counted colonies containing $>20$ cells after staining with Coomassie blue.

Senescence-associated $\beta$-galactosidase staining. We stained cryosections of mouse kidney for senescence-associated $\beta$-galactosidase activity according to manufacturer's protocol (Cell Signaling Technology). To quantify MEFs stained for senescence-associated $\beta$-galactosidase activity, we counterstained cells with Hoechst to visualize nuclei. The percentage of senescent cells was the total number of senescent cells divided by the total number of cells counted using immunofluorescence $(n=3$ MEF lines per genotype).

Collection and analysis of metaphase II oocytes and in vitro fertilization. We collected ovulated oocytes and instantly fixed them as previously described ${ }^{27}$. We stained fixed oocytes with $\alpha$-tubulin (1:1,000 dilution of T-9026, Sigma) and Hoechst and analyzed them by confocal microscopy. We carried out in vitro fertilization experiments as previously described ${ }^{28}$. We obtained aged testes from the aged rodent tissue bank maintained by the National Institute of Aging (Bethesda).

Note: Supplementary information is available on the Nature Genetics website.

\section{ACKNOWLEDGMENTS}

We thank J. Harden, R. Babu, M. Gazi, S. Guyse, M. Pittelkow, R. Goorha, J. Davenport, D. Pearson, K. Hafner (Cytogenetics Shared Resource), J. van Ree and S. Kaufman for supporting this project; R. Bram for critically reviewing the manuscript and for discussions; and T. Yen for providing BubR1 antibody. This work was supported by a grant from the US National Institutes of Health.

\section{COMPETING INTERESTS STATEMENT}

The authors declare that they have no competing financial interests.

Received 30 March; accepted 7 May 2004

Published online at http://www.nature.com/naturegenetics/

1. Hassold, T. \& Hunt, P. To err (meiotically) is human: the genesis of human aneuploidy. Nat. Rev. Genet. 2, 280-291 (2001).
2. Thomas, N.S. et al. Maternal sex chromosome non-disjunction: evidence for $X$ chromosome-specific risk factors. Hum. Mol. Genet. 10, 243-250 (2001).

3. Jallepalli, P.V. \& Lengauer, C. Chromosome segregation and cancer: cutting through the mystery. Nat. Rev. Cancer 1, 109-117 (2001).

4. Wassmann, K. \& Benezra, R. Mitotic checkpoints: from yeast to cancer. Curr. Opin. Genet. Dev. 11, 83-90 (2001).

5. Yu, H. Regulation of APC-Cdc20 by the spindle checkpoint. Curr. Opin. Cell Biol. 14, 706-714 (2002)

6. Cleveland, D.W., Mao, Y. \& Sullivan, K.F. Centromeres and kinetochores: from epigenetics to mitotic checkpoint signaling. Cell 112, 407-421 (2003).

7. Wang, Q. et al. BUBR1 deficiency results in abnormal megakaryopoiesis. Blood 103 , 1278-1285 (2004)

8. Babu, J.R. et al. Rae1 is an essential mitotic checkpoint regulator that cooperates with Bub3 to prevent chromosome missegregation. J. Cell Biol. 160, 341-353 (2003).

9. Michel, L.S. et al. MAD2 haplo-insufficiency causes premature anaphase and chromosome instability in mammalian cells. Nature 409, 355-359 (2001).

10. Hasty, P., Campisi, J., Hoeijmakers, J., van Steeg, H. \& Vijg, J. Aging and genome maintenance: lessons from the mouse? Science 299, 1355-1359 (2003).

11. Campisi, J. Cancer and ageing: rival demons? Nat. Rev. Cancer 3, 339-349 (2003).

12. Parrinello, S. et al. Oxygen sensitivity severely limits the replicative lifespan of murine fibroblasts. Nat. Cell Biol. 5, 741-747 (2003).

13. Lengauer, C., Kinzler, K.W. \& Vogelstein, B. Genetic instabilities in human cancers. Nature 396, 643-649 (1998).

14. Li, R., Sonik, A., Stindl, R., Rasnick, D. \& Duesberg, P. Aneuploidy vs. gene mutation hypothesis of cancer: recent study claims mutation but is found to support aneuploidy. Proc. Natl. Acad. Sci. USA 97, 3236-3241 (2000).

15. Cahill, D.P. et al. Mutations of mitotic checkpoint genes in human cancers. Nature 392, 300-303 (1998)

16. Shichiri, M., Yoshinaga, K., Hisatomi, H., Sugihara, K. \& Hirata, Y. Genetic and epigenetic inactivation of mitotic checkpoint genes hBUB1 and hBUBR1 and their relationship to survival. Cancer Res. 62, 13-17 (2002).

17. Ford, W.C. et al. Increasing paternal age is associated with delayed conception in a large population of fertile couples: evidence for declining fecundity in older men. The ALSPAC Study Team (Avon Longitudinal Study of Pregnancy and Childhood). Hum. Reprod. 15, 1703-1708 (2000).

18. Eskenazi, B. et al. The association of age and semen quality in healthy men. Hum Reprod. 18, 447-454 (2003).

19. Meyers, E.N., Lewandoski, M. \& Martin, G.R. An Fgf8 mutant allelic series generated by Cre- and Flp-mediated recombination. Nat. Genet. 18, 136-141 (1998).

20. Kasper, L.H. et al. CREB binding protein interacts with nucleoporin-specific FG repeats that activate transcription and mediate NUP98-HOXA9 oncogenicity. Mol. Cell. Biol. 19, 764-776 (1999).

21. Feldmann, K.A., Pittelkow, M.R., Roche, P.C., Kumar, R. \& Grande, J.P. Expression of an immediate early gene, IEX-1, in human tissues. Histochem. Cell Biol. 115, 489-497 (2001)

22. Nagy, T.R. \& Clair, A.L. Precision and accuracy of dual-energy X-ray absorptiometry for determining in vivo body composition of mice. Obes. Res. 8, 392-398 (2000).

23. Tyner, S.D. et al. p53 mutant mice that display early ageing-associated phenotypes. Nature 415, 45-53 (2002).

24. Wassmann, K. \& Benezra, R. Mad2 transiently associates with an APC/p55Cdc complex during mitosis. Proc. Natl. Acad. Sci. USA 95, 11193-11198 (1998).

25. Koomen, M. et al. Reduced fertility and hypersensitivity to mitomycin C characterize Fancg/Xrcc9 null mice. Hum. Mol. Genet. 11, 273-281 (2002).

26. de Boer, J. et al. Premature aging in mice deficient in DNA repair and transcription. Science 296, 1276-1279 (2002).

27. Woods, L.M. et al. Chromosomal influence on meiotic spindle assembly: abnormal meiosis I in female MIh1 mutant mice. J. Cell Biol. 145, 1395-1406 (1999).

28. Kang-Decker, N., Mantchev, G.T., Juneja, S.C., McNiven, M.A. \& van Deursen, J.M Lack of acrosome formation in Hrb-deficient mice. Science 294, 1531-1533 (2001). 